\title{
Comparative Study of Recognition Differences in Personal Health Record Users between South Korea and the United States
}

\author{
Robert James Campbell ${ }^{1}$, Tae-Ro Lee ${ }^{2}$, Mi Sun Kim ${ }^{2}$, Eun-yeob Kim ${ }^{3}$, Seoung Woo Ham ${ }^{4}$, \\ Hyun-Sill Rhe ${ }^{2, * *}$ \\ ${ }^{1}$ Department of Health Services and Information Management, East Carolina University, N.C., U.S.A \\ ${ }^{2}$ Department of Healthcare Management, Korea University, Seoul, Korea \\ ${ }^{3}$ Dep artment of Health Administration, Seoy eong University, Gwangju, Korea \\ ${ }^{4}$ Department of Medical Record, Korea Institute of Radiological \& Medical Sciences, Seoul, Korea
}

\begin{abstract}
Compared to S. Korea, the United States has been promoting the utilization of personal health records better, especially with the use of online patient portals. Additionally, with the Health Information Act (HIT) and mean ingful use criteria, personal health record (PHR) is being re-emphasized to influence the health reform. The U.S. adopted PHR at facilities, including hospitals and ambulatory care centers, whereas the Korean market for PHR is relatively new. However, the level of awareness and utilization of the general public is low in both countries. Thus, to increase awareness and utilization of PHR, this study aimed to co mpare similarities and differences in the definition, background, utilization, and barriers of PHR between the United States and Republic of Korea. Three published references were reviewed and compared: the Lake Research Partners for the California HealthCare, the Markle Foundations in the U.S., and the Center for Interoperable Electronic Health Record (CIEHR) in Korea. We utilized published reports on definition, background, and function; we also analysed our surveyed data collected in S. Korea in 2008. The data in the three literatures along with the survey data collected in Korea were all gathered from the general public. The result showed that the proportion of PHR users and non-users in the United State (85\%) and S. Korea (81\%) were similar. According to Lake Research, 32\% of 266 A merican PHR users agreed that PHR is helpful on improving their own health. In addition, $32.4 \%$ responded that PHR is useful to the control risk factors for health. The total number of women respondents $(35 \%)$ in the U.S. was higher than that of men $(31 \%)$, but the number of women respondents $(30.8 \%)$ in Korea was lower than that of men $(33.9 \%)$. The barriers for using PHR for non-users in the U.S. included concerns of privacy (75\%), according to the Lake Report. In our survey, $53.4 \%$ of Korean non-users of PHR were also concerned about the privacy of their personal information. Although there was a lack of recognition differences, it is important to enhance the quality of healthcare through effective utilization of PHR. W ith the fact that PHR systems should be tailored for different disease patterns, healthcare systems, and culture, these similarities and differences of recognition as well as perceptions of PHR can be foundational works to conduct future research on comparisons of implementing strategies, issues of governance and policy, and much more.
\end{abstract}

Keywords Personal Health Record (PHR), PHR Recognition, Comparative Study

\section{Introduction}

In healthcare, correct patient information can lead to proper diagnoses, treatments, and preventions of diseases. However, having timely access to needed information is not always easy. Information on previous care history, allergies, and family histories can be stored on paper or electronic records maintained by multiple healthcare providers. The

* Corresponding author:

pridehyun@korea.ac.kr (Hyun-Sill Rhee)

Published online at http://journal.sapub.org/phr

Copyright (C) 2012 Scientific \& Academic Publishing. All Rights Reserved most current medication list can present a challenge if the only place they are stored is in the patient's own memory. To overcome these problems, healthcare organizations, professionals, and admin istrators are calling for a universal adoption of electronic health records (EHRs) and personal health records (PHRs). Further, the Institute of Medicine (IOM) stated in its 2003 report that the optimal electronic medical records (EMRs) should include the provider-maintained part and the PHR[1]. Since EMR is provider-centered, PHR can provide the patient-centered access to information. An individual may create his or her PHR using commercially availab le applications from stand-alone systems to web-based applications. Also, integrating PHR with EHR will provide much greater benefits than a 
stand-alone PHR[2].

Originally, PHR was used to encourage individuals to take more responsibility for their health using a client-held health record, known as Personal Life Health Plan (PLHP). It has also been developed to teach individuals to use the PLHP, to consolidate that use, and to integrate a PLHP into the individuals' lives and their interactions with health professionals[3]. The concept of using parent-held Personal Child Health Records (PCHRs) in the United Kingdom began in 1981[4]. The record booklets, developed in England, were used by parents, doctors, and community nurses to build up an independent chronological record of child birth statistics, health, immunization, growth rate, developmental checks, and contacts with the health service[5].

Patient-held health records have been used successfully to improve communications, to allow patients to audit data quality, to prompt them to attend review sessions, and to identify gaps in their knowledge. Patient-held health records for particular illnesses, such as hypertension and diabetes, have been well accepted by both practitioners and patients[6]. A Patient-Centered Health Record (PCHR) is a personal health record that is patient-owned, is patientmanaged, and represents health information significant to patients in ways they prefer[7]. In Australia, Personal Health Record Booklets (PHRBs) represent a potentially cost- effective way to use screening tests and to improve cancer prevention[8].

In particular, with the Patient Protection and Affordable Care Act and the mean ingful use criteria, utilization of PHR has been gathering momentum in the United States[9]. The agenda of Health information technology (HIT) act emphasized that 'effective management of personal health information (PHI) empowers patients to actively partner with their healthcare providers in making important healthcare decisions, which can potentially lead to better healthcare and better health outcomes' $[10]$. PHR is being positioned as an antidote to the healthcare reform and are being requested by employers[11]. Also, the U.S. has done a much better job at promoting the utilization of PHR compared to S. Korea, especially through patient portals via web site of health care facilities[12]. However, the low level of awareness and utilization of PHR are similar in both countries. The aim of this study was to compare the background and history, usage, functions, preferences, and barriers of PHR between the United States and the Republic of Korea, which provide healthcare services differently, as a first step toward increasing awareness and utilization of PHR.

\section{Methods}

\subsection{Survey and Participants}

The survey on the recognition of PHR was conducted over a 3-week period in Seoul in May 2008. The surveyors were comprised of 20 university students who visited various healthcare institutions and universities to conduct the survey.
There were 695 participants, including adults and university students.

Before commencing each survey, the surveyor explained the concept of PHR to each part icipant through a face-to-face presentation, since most individuals did not fully understand the concept of PHR. Out of 567 cases, we excluded 128 (18.4\%) cases with incomplete and uncertain data. Then, we extracted data over 20 years in length and compared them to the data based on the published Lake Research Report of the California HealthCare Foundation in the United States.

\subsection{Questionnaires and Analysis}

The PHR questionnaires included the following categories: Recognition \& Education (5 items), Utilization \& Willingness (11 items), and Privacy \& Security (2 items). The structured questionnaires scored from strongly disagree (1 score) to strongly agree (5 scores) according to the Likert scale. Multiple-choice questions were also included.

We used 10 questions from a pool of 18 to compare the published Lake Research Report and other items with our surveyed data. Then, we converted the results into identical units to enable comparison. We mainly used frequency analysis and descriptive statistics by Microsoft Excel ${ }^{\circledR}$ because we did not have any raw participant data from the U.S.

\subsection{Comparison}

To compare the responses for the PHR questionnaires between participants in the U.S. and Korea, we used published references from Lake Research Partners for the California HealthCare Foundation (Undem, 2010) and the Markle Foundation (Bingman et al., 2003) in the United States. However, the number of published articles on Korean PHR was less compared to that of the U.S. As a result, we used the published reports on definition, background, and function by CIEHR (Center for Interoperable EHR), and our surveyed PHR data were used to compare recognition.

\section{Results}

\subsection{Definition, Attribution, and Function}

\subsubsection{Definition}

The American Health Information Management Association (AHIMA) defines a PHR as "an electronic, universally available, life long resource of health information needed by individuals to make health decisions. Individuals own and manage the information in the PHR, which comes from healthcare providers and the individual. The PHR is maintained in a secure and private environment, with the individual determining rights of access. The PHR is separate from and does not replace the legal records of any provider"[13].

The definition of PHR by CIEHR in Korea is as follows: 
"a set of tools for managing personal lifelong health records provided by various medical facilities as well as those created by the individual fro $m$ the integral and comprehensive perspective. PHR must be protected by the personal information protection law and by the latest security technology, maintained by the individual (or a proxy appointed by the individual),and be accessible when necessary regardless of time and location (Homedoctor, 2010; Seoul National University Hospital, 2010)."

At present, AHIMA's definition has been accepted as the core concept of PHR. The Markle Foundation and Healthcare Information and Management Systems Society (HIMSS) have also adopted the internet-accessible electronic form as the basic concept of PHR[14]. In Korea, CIEHR's PHR definition remains as the only one in existence.

\subsubsection{Attribution}

The Connecting for Health Personal Health Working Group[15] believes that all PHRs should have the following attributes:

In the United States

a) The PHR should contain health information that spans the life of the individual.

b) The PHR should contain information gathered fro $m$ all healthcare providers and facilities where an individual has received care.

c) The PHR should be accessible from any location at any time of the day.

d) The PHR must be private and secure.

e) The PHR must be transparent so that an individual can see who entered information into the record, where it was transferred, and who viewed the information.

f) The PHR must also be able to exchange health in formation between different providers and different healthcare organization.

In Korea

a) Unlike a single treatment or a health record, PHR must consist of every health record saved in the system and all treatment records stored at multip le medical facilities.

b) The treatment and health records should be accessed regardless of time and location.

\subsubsection{Function}

To provide a clearer understanding of the functionality involved with a PHR, AHIMA uses 6 attributes to describe the tasks to be performed by a standard PHR, which include the following: ownership, function, format and content, privacy and access, maintenance, and interoperability.

In the United States

a). Ownership: The PHR should be owned by the individual for whom the record is created to host his/her health information.

b). Function: The main task of the PHR is to help organize information once stored on paper into an electronic format while presenting clinical concepts in layman's terms and, if necessary, translating information into the individ- ual's native language. The user interface should be easy to read and allow for custom tailored views of stored information as well as allow for important data to be shared with other clinicians and healthcare organizations. A PHR should be portable, allow patients to refill prescriptions, and be useful in making better healthcare decisions. For example, a patient with a family history of colon cancer can be reminded by a PHR to obtain a colonoscopy appointment as recommended by his/her healthcare provider, consistent with the current best practice.

c). Format and Content: The format and content of the PHR should be dynamic. This means that the record is continually updated through a manner in which it can store and accept paper documents, and it can be linked to an individual provider's PHR. Furthermore, the original and immediate source of all information is identifiable and includes date of entry and occurrence.

d). Privacy and Access: The PHR should be private, secure, and requires a username and password to gain access to stored information. The PHR should be accessible from any place at any time and provide a mechanism that allows emergency access to healthcare professionals. Finally, the individual should be responsible for all information contained in the record.

e). Maintenance: The PHR should provide audit trails showing the information viewed by whom and on what data. More importantly, to maintain the integrity of the record, data can only be amended by the orig inal source, with the individual owner ultimately decid ing what should be incorporated into the record.

f). Interoperability: The PHR must use current standards in order to enable data exchange between an individual's healthcare providers and facilitate where they receive care. The PHR should also use a defined vocabulary. For example, Systematized nomenclature Of Medicine (SNOMED) stores health information and provide links to other health information sources to provide detailed explanations of a patient's illness, test results, and medications.

\section{In Korea}

a). Integral and Comprehensive Perspective: The PHR system incorporates treatment records from every personal visit to health providers. The system provides a comprehensive reference according to the types of disease and period rather than a simple chronological list.

b). Ownership, Management and Exchange by Individuals (or proxies appointed by individuals): all information contained in the PHR system can be owned and maintained by individuals or viewed by proxies appointed by individuals for a specific period.

c). Ability to Insert and Receive Information: Information stored in the PHR system consists of personal treatment records from medical providers as well as daily physiological information (e.g., height, weight, blood pressure, blood sugar level) recorded by individuals.

d). Communication hub: The PHR system resembles an Internet portal and provides a co mmon tool for communication links. 
e). Protecting Privacy and Security: Since data stored in the PHR system is sensitive personal health information, it must be maintained according to legal standards and protected with the latest security technologies.

\subsection{Background and History}

T.H. Lee et al.[16] describe healthcare in the U.S. to be in a state of chaos, where patients with multiple diseases are being treated by multiple providers at multiple facilities and are taking a number of medications to control their symptoms. Associated with these epis odes of care are examination reports, vital signs, radiology reports, laboratory test reports, prescriptions for medications, and treatment plans stored in paper format that are not easily shared with other providers. The problem lies in the fact that in most cases, only patients have all the information regarding the care they have received throughout their lives, which places responsibilities on them to recall all appropriate health information each time they visit a healthcare provider. In addition, the clinician must bring out relevant information to enable proper diagnoses and quality treatments. To help reverse this problem, the PHR is being taunted as a means to fully document a patient's health information, from birth to death and more importantly, to provide a platform to adjust care between a patient's healthcare providers.

A computer-based record in healthcare was recommended as early as in 1991 by the Institute of Medic ine (IOM), which called it as "an essential technology for patient care"[17]. This report was updated in 1997[18], followed by the IOM's To Err Is Human report in 1999, which focused the nation's attention on medical errors[19]. Since then, several additional national expert panels have advocated the widespread application of healthcare information technology[20-25].

In Korea, the healthcare delivery model focuses on healthcare consumers to enable consumer protection while strengthening their rights to know and to facilitate health service selections. Medical expenditure is increased due to changes in health policy related to medical service, continued reorganization of health management system, opposition of expanding health promotion projects for health related activities and disease preventions, political demands for healthcare service reform and accessibility improvement of medical service, and information using information technology. Changes in consumer a wareness and dis ease patterns due to aging are rising in Ko rea[26]. The U.S., in addition, is under pressure from an epidemic of preventable diseases, such as obesity, heart diseases, and diabetes. Chronic diseases account for $70 \%$ of all deaths in the U.S. - about 1.7 million deaths each year. These diseases also impose major limitations on the daily living of almost 1 out of 10 A mericans or about 25 million people[27]. Additionally, in 2008, the Korean Institute for Health and Social Affairs reported that 7 out of 10 main causes of death included chronic diseases, such as cancer $(28 \%)$, cerebrovascular disease $(11.3 \%)$, heart disease $(8.7 \%)$, diabetes $(4.2 \%)$, liver disease
(2.9\%), and hypertension (1.9\%)[28]. In 2008, the number of Korean patients with hypertension was $9.7 \%$, whereas $3.6 \%$ had diabetes. The medical costs for the treatment of hypertension accounted for $17.9 \%$, and diabetes accounted for $9.6 \%$ of total healthcare budget, according to the National Health Insurance Company[29].

Healthcare providers perform poorly in terms of providing quality, safe, efficient, and patient-centered care. Additional healthcare resources required for escalated healthcare costs are associated with the aging population, which are also elevated by the number of uninsured persons [30] due to changes in healthcare problems. For example, Hurricane Katrina exposed the grave weakness in the health information infrastructure. When confronted by a hurricane, an avian flu pandemic, or a bioterroris $m$ attack, the public needs to have dependable access to their health information $[5,21,31]$. Therefore, it is necessary to possess PHR in order to monitor individual health status, to prevent chronic diseases, and to safeguard personal health information.

\subsection{Recog nition}

\subsubsection{Demography of PHR Users and Non-users}

The demography of our surveyed participants is as follows: wo man $(51.5 \%)$, age ranged from 20 to 73 , and $73.7 \%$ were under the age of 45 . Nearly 7 out of 10 participants responded that they would use PHR if they were made available[32]. PHR non-users among surveyed participants by the Lake Report accounted for $85 \%$, and the proportion of PHR non-users in our surveyed data in Korea was $81 \%$ (Table 1).

Table 1. Demographic characteristics

\begin{tabular}{ccc}
\hline & The United States ${ }^{1}$ & $\begin{array}{c}\text { Republic of } \\
\text { Korea }\end{array}$ \\
\hline Total & $100 \%(n=1,849)$ & $100 \%(n=567)$ \\
PHR non-Users & $85 \%(n=1,583)$ & $81 \%(n=459)$ \\
PHR Users & $14.4 \%(n=266)$ & $19 \%(n=108)$ \\
- Men aged (29 to 45) & $11 \%$ & $14 \%$ \\
\hline
\end{tabular}

1) Lake Research, Partners for the California HealthCare Foundation (2010).

\subsubsection{What is Useful and of Interest about PHR?}

According to the Lake Research, 32\% of 266 PHR users responded "yes" to the question, "Does PHR lead you to do something to improve your health". In our surveyed results, $32.4 \%$ responded that PHR is useful to control risk factors for health. Women respondents (35\%) in the U.S. are higher than men respondents $(31 \%)$, but the number of women respondents $(30.8 \%)$ in Korea was lower than that of men respondents (33.9\%). The Lake Research surveyed people between 29 and 45 years of age. Thus, we compared respondents in the same age group (Table 2). 
Table 2. Response to the Question, "Does PHR lead you to do something to improve your health?"

\begin{tabular}{|c|c|c|}
\hline & $\begin{array}{c}\text { The United } \\
\text { States }{ }^{1)} \\
(n=266)\end{array}$ & $\begin{array}{l}\text { Republic of Korea } \\
\qquad(n=108)\end{array}$ \\
\hline Yes & $32 \%$ & $32.4 \%$ \\
\hline Age $<45$ & $24 \%$ & $32.3 \%$ \\
\hline Age $45+$ & $43 \%$ & $33.3 \%$ \\
\hline Men & $31 \%$ & $33.9 \%$ \\
\hline Women & $35 \%$ & $30.8 \%$ \\
\hline$<2$ Chronic Conditions & $24 \%$ & $69.2 \%$ \\
\hline $2+$ Chronic Conditions & $40 \%$ & $28.2 \%$ \\
\hline
\end{tabular}

According to the Lake Research, usage of PHR among PHR users included test results review (57\%), renewing prescription online (52\%), and reading doctor's instructions $41 \%$ ). Participants in Korea, however, used PHR to confirm the results of investigations $(67.6 \%)$, review doctor's instructions (44.4\%), and renew prescriptions (28.7\%). 50\% of participants among the non-PHR users in the U.S. are interested in obtaining prescriptions online $(48 \%)$ and looking at test results $(40 \%)$. In Korea, $76 \%$ of non-PHR users are interested in reviewing test results, reviewing prescriptions $(37.5 \%)$, and reading doctor's instructions online (34.2\%) (Table 3).

Table 3. Response to the Question, "What is useful or what are you interested about PHR?"

\begin{tabular}{ccccc}
\hline & \multicolumn{2}{c}{ The United States ${ }^{1)}$} & \multicolumn{2}{c}{ Republic of Korea } \\
\cline { 2 - 5 } & $\begin{array}{c}\text { Users } \\
(n=266 \\
\end{array}$ & $\begin{array}{c}\text { Non-Users } \\
(n=1,583)\end{array}$ & $\begin{array}{c}\text { Users } \\
(n=108\end{array}$ & $\begin{array}{c}\text { Non-Users } \\
(n=459)\end{array}$ \\
\hline $\begin{array}{c}\text { - Looking at } \\
\text { test results } \\
-\begin{array}{l}\text { Renewing } \\
\text { Prescription } \\
\text { online }\end{array}\end{array}$ & $57 \%$ & $40 \%$ & $67.6 \%$ & $76.0 \%$ \\
$\begin{array}{c}\text { - Seeing doc- } \\
\text { tor's } \\
\text { instructions }\end{array}$ & $41 \%$ & $50 \%$ & $28.7 \%$ & $37.5 \%$ \\
\hline 1) Lake Research, Partners for the Cali fornia HealthCare Foundation (2010).
\end{tabular}

\subsubsection{Barriers and Privacy}

Concerns about privacy are a barrier to using a PHR for $75 \%$ of the participants. $61 \%$ selected 'don't need this to handle my health needs', which is a also barrier to using a PHR. Next, $26 \%$ of participants in the U.S. chose 'don't like the computer/internet'. In our surveyed data, concerns about privacy are a barrier to using a PHR for $53.4 \%$, and $10.2 \%$ of respondents chose 'don't need this to handle my health needs' while $13.1 \%$ selected 'I don't like the computer/internet' (Table 4).
Table 4. Barriersto Using a PHR for Non-user PHR

\begin{tabular}{lcc}
\hline & $\begin{array}{c}\text { The United States } \\
(n=1,583)\end{array}$ & $\begin{array}{c}\text { Republic Of } \\
\text { Korea } \\
(n=459)\end{array}$ \\
\hline $\begin{array}{c}\text { Don't like the computer or } \\
\text { Internet }\end{array}$ & $13.1 \%$ \\
$\begin{array}{c}\text { Worry about the privacy of } \\
\text { my information }\end{array}$ & $75 \%$ & $53.4 \%$ \\
$\begin{array}{c}\text { Don't need thisto handle } \\
\text { my health needs }\end{array}$ & $61 \%$ & $10.2 \%$ \\
\hline${ }^{1)}$ Lake Research, Partners for the Cali fornia HealthCare Foundation $(2010)$.
\end{tabular}

\section{Discussion}

The majority of patients experienced the PHR for personal use as well as a reference and knowledge source. While $74 \%$ envisaged its use by other practitioners, only $56 \%$ were considered as its users. Only the patients presenting their PHRs to hospitals reported that other healthcare providers may use their PHRs[33]. Two hundred $(n=200)$ wo men (148 shared care patients and 52 clinic patients) completed a questionnaire on care received during pregnancy and the use of a patient-held record. Women receiving shared care reported higher levels of satisfaction with their care than clin ic patients who did not receive the report[34]. People recognized many benefits of having a PHR, such as helping them understand doctors' instructions (71\%). $89 \%$ of patients said they found the PHR 'helpful' or 'very helpful'. Elements of PHR of the greatest interests are as follows: to exchange emails with personal doctor $(75 \%)$, to track immunization records $(69 \%)$, to note mistakes in my record $(69 \%)$, to transfer in formation to new doctors $(65 \%)$ and to obtain and track test results $(63 \%)$ (David, 1993). The benefits of using PHR are to reduce redundant tests $(34.5 \%)$, to facilitate accurate diagnoses and treatments by the providers $(31.1 \%)$, and to acquire accurate knowledge by patients (25.9\%)[26]. Regarding the use of PHR, the statement 'I felt more satisfied with my visit' was strongly agreed by $13 \%$ of the participants and agreed by $26 \% .55 \%$ responded with 'neither,' and $6 \%$ responded with 'disagree'. When asked the following question, 'Based on your experience using the journal, would you recommend it to a friend or relative?,' $56 \%$ responded with 'yes', whereas $14 \%$ answered 'no', and 30\% answered 'not sure' [35].

One-third of the patients preferred a credit card or wallet sized format, whereas the other responses were as follows: $20 \%$ the pocket sized, $15 \%$ the blue book folder format, $9 \%$ the index card in holder format, and 5\% the folded A4 paper in holder format. A computer-based PHR or a s mart card is possibly more effective as it removes double entry with a paper-based PHR and renders the information stored to be more accessible[33].

According to patients/healthcare providers, the best features of the PHR are as follows: records' capability to collect and capture appropriate data using the diary section, 
blood count flow sheets, height and weight recording sheets, and self-medication sheets[36]. In preference to the PHR, almost half of the public $(46.5 \%)$ stated they would be interested in joining a free online PHR system in the U.S. (Bing man et al., 2003), and $36.4 \%$ of adult respondents and $71.1 \%$ of university students were interested in using an online PHR, according to the research in Korea[37]. Also, according to a report published by the Markle Foundation in 2003 , over $60 \%$ of respondents are interested in using at least one feature of an online medical record at the present or sometime in the future[15].

Patients receiving a computer-generated patient-held medical record summary (CHR) as a part of a mail recruitment were more likely to attend for a check-up $(\mathrm{P}=0.016)$. Those receiving both $\mathrm{PHR}$ and $\mathrm{CHR}$ were more likely to keep $(\mathrm{P}=0.014)$ and use $(\mathrm{P}=0.029)$ the records [38].

About $70 \%$ of people aged 25-34 wanted online access to their medical records while only $35 \%$ of those over the age of $65 \mathrm{did} .83 \%$ of healthcare consumers wanted lab test results available online; $69 \%$ wanted online charts for managing chronic diseases, and $80 \%$ wanted to receive personalized medical information online from their practitioners after each clinic visit. Most Americans do not keep their health records at home while $40 \%$ of A mericans keep health records in paper format. Only $2.7 \%$ said they have an electronic PHR today. The $2.7 \%$ of respondents reported that they visited their doctors more than seven times in the past year for follow-up of their long-term health problems, such as disability and poor health[15].

Consumers reacted very optimistically to the idea of having online access to their medical information by PHR: $83 \%$ of healthcare consumers wanted lab test reports available online, $80 \%$ wanted to receive personalized medical information online fro $\mathrm{m}$ their practitioner after a clin ic $\mathrm{v}$ is it, and $69 \%$ wanted online charts to manage chronic diseases[15]. A PHR can be used as easy as a paper file or a notebook maintained by an individual. It can also be as sophisticated as an electronic document maintained on a personal computer or a website[32]. 85\% of respondents were satis fied with the convenience, and $94 \%$ of them were satisfied with the overall online referral process of web-based personal records in 2004[39].

The general categories of barriers include: access to PHR systems, access to computers or devices, cognitive disabilities, physical disabilities, low literacy, and low computer and low health literacy[40]. Consumers' concerns with sharable patient information using PHR include: leakage of patient information $(57.2 \%)$, hospitals not using past medical records $(16.9 \%)$, high costs for the system $(14.2 \%)$, and hospitals not providing past medical records[26].

There were several limitations to this study. First, there was a lack of data to compare information to show descriptive statistics. Specific comparisons need to be investigated further in future studies. Secondly, there was lack of recognition in different healthcare systems. The quality of care through effective utilization of the PHR may be investigated based on standardized questionnaires. The individual char- acteristics of health problems include cultural differences, which need to be considered.

\section{Conclusions}

We compared the PHR and the perceptions of the users and non-users in the U.S. and Korea and found both similarities and differences. One-third of the PHR-users responded that PHR helped to improve their health in both countries. Next, in the United States, barriers for using PHR for non-users included concerns of privacy of their personal information (75\%); $53.4 \%$ of Korean non-users of PHR were also concerned about the privacy. This study could be a foundational work for future comparative research on PHR and related topics between the two countries. The characteristics of ideal PHR for the United States and South Korea, considering its culture, demographical needs, healthcare delivery systems, policy, etc., should be considered. Additionally, PHR is serving as an evidence in the investigations of the characteristics of patients and the types of diseases to improve the health outcome or health behavior in both countries; this topic can be a critical study. In the future, a comparative study related to the governance and policy of PHR in the two countries could also be beneficial. For instance, one study conducted in the United States stated that a minimum PHR governance structure will improve the policy process for PHR and also proposed a governance model[41]. Also, there is a research pointing out that patient activation and health behaviors have positive correlation[42]; however, studies on whether access to health information will improve patient participation and/or improve health outcomes are limited. Despite the fact that there is lack of literature, PHR continues to be a hopeful outlook to increase patient participation and health outcomes. Moreover, a recent study showed that only few patients actually utilized the PHR when provided with it[43]. Therefore, further research should be done in both countries on how to empower and educate patients to increase participation and improve health outcomes. Again, this study can be a foundational work for further comparative research on the topic of PHR.

\section{ACKNOWLEDGEMENTS}

This work was supported by a grant from the Korea University (\#K0822341).

\section{REFERENCES}

[1] P.C. Tang, Key Capabilities of an Electronic Health Record System. Washington, DC: Institute of Medicine of the National Academies, 2003.

[2] P.C. Tang, J.S. Ash, D.W. Bates, J.M. Overhage, D.Z. Sands, 
"Personal health records: definitions, benefits, and strategies for overcoming barriers to adoption", J. Am. Med. Inform. Assoc. ,vol.13, no. 2,pp.121-126, 2006.

[3] R. Giglio, B. Spears, D .Rumpf, N. Eddy, "Encouraging behavior chan ges by use of client-held health records", Med. Care, vol.16, no.9, pp. 757-764,1978.

[4] R. Knowles, M. Blackburn, M. Zahir, M. Russell, A. Carrier, E. Nevrkla, "The implementation of a new parallel child health record", Child Care Health,vol.25,no.4, pp.253266,1999 .

[5] A.D. Lakhani, A. Avery, A. Gordon, N. Tait, "Evaluation of a home based health record booklet", Arch. Dis. Child,vol.59, no.11,pp. 1076-1081,1984.

[6] R. Jones, J.McConville, D. Mason, L. Macpherson, L. Naven, J. McEwen, "Attitudes towards, and utility of, an integrated medical-dental patient-held record in primary care", Br. J. Gen. Pract,vol.49,no.442,pp. 368-373,1999.

[7] A. Stoly ar, W.B. Lober, D.R. Drozd, J. Sibley, "Feasibility of data exchange with a Patient-centered Health Record", AMIA. Annu Symp Proc., 1123,2005.

[8] S.A. Newell, R.W. Sanson-Fisher, A. Girgis, H.M. Davey, "Can personal health record booklets improve cancer screening behaviors?”, Am. J. Prev. Med.,vol.22,no.1,pp. $15-22,2002$

[9] Department of Health and Human Services. Centers for Medicare \& Medicaid Services, "EHR Meaningful Use Overview", 2011. Available at https://www.cms.gov/EHRIn centivePrograms/30_Meaningful_Use.asp ,accessed May 2011.

[10] C. Wilson, A. Peterson, Managing Personal Health Information: An Action Agenda: (Prepared by Insight Policy Research under Contract No. HHSA290200710072T), Agency for Healthcare Research and Quality March 2010 Contract No.: AHRQ Publication no. 10-0048-EF. Rockville, MD: Agency for Healthcare Research and Quality, 2010:1.

[11] Boehm EW. Forrester Research Inc. PHRs: from evolution to revolution, Cambridge, 2007. 18 p[F] J. D. Halamka, K. D. Mandl, P. C. Tang, Early Experiences with Personal Health Records, Journal of the American Medical Informatics Association, vol.14, no.1,pp.1-7,2008.

[12] American Health Information Management Association, Personal Health Record, 2011, Available at: http://www. ahima. org/resources/phr.aspx, accessed April 20, 2011.

[13] Healthcare Information and Management Systems Society, Personal Health Record, 2011, Available at: http://www. himss.org/A SP/topics_phr.asp, accessed April 20, 2011

[14] Markle Foundation, "The Personal Health Working Group: Final Report. 2003”, Available at: http://library. ahima.org/ xpedio/groups/public/documents/external/bok1_024234.pdf, accessed April 20, 2011.

[15] T.H. Lee, J.J. Mongan, "Chaos and Organization in Health Care", first ed. The MIT Press, London, 2009. Available at: http://www.partners.org/international/internl_media/Lee-intr o.pdf, accessed at April 20, 2011.

[16] R.S. Dick, E.B. Steen, “The Computer-based Patient Record: An Essential Technology for Health Care", National Academy Press, Washington, D.C., 1991.
[17] R.S. Dick, E.B. Steen, D.E. Detmer, "The Computer-based Patient Record: An Essential Technology for Health Care", National Academy Press, Rev. ed. Washington D.C., 1997.

[18] L.T. Kohn, J.M. Corrigan, M.S. Donaldson, "To err is human: building a safer health system", National Academy Press, Washington, D.C., 2000.

[19] P.A. spden, "Patient safety: achieving a new standard for care", National Academies Press, Washington, D.C., 2004.

[20] W.C. Richardson, D.M. Berwick, J.C. Bisgard, L.R. Bristow. C.R. Buck, C.K. Cassel, "Crossing the Quality Chasm: A new health system for the 21 st centry", National Academy Press, Washington D.C., 2001. Available at: http://www.nap. edu/ html/quality_chasm/reportbrief.pdf, accessed at April 20, 2011.

[21] C.M. Laiacona, "Networking health: Prescriptions for the Interne”t, J. Gov. Inform,vol.28,no.3,pp. 303-305,2001.

[22] R. Reddy, I. Wladawsky-Berger, "Transforming Health Care through Information Technology", Report to the President, President's Information Technology Advisory Committee,Washington, D.C., 2001. Available at: http://www.nitrd. gov/ Pubs/pitac/pitac-hc-9feb01.pdf, accessed at April 20, 2011.

[23] J.R. Lumpkin, "Information for Health: A Strategy for Building the National Health Information Infrastructure", U.S. Department of Health and Human Services, Washington, D.C., 2001.

[24] J. Corrigan, A. Greiner, S.M. Erickson, "Fostering rapid advances in Health Care: learning from system demonstrations", The National Academies Press, Washington, D.C., 2003.

[25] Center for interoperable EHR, The PHR Situation Analysis, Seoul, 2008.

[26] "The Business of Immunization Registry", 2010, Available at: http ://nip.cdc.go.kr. accessed at November 13, 2010.

[27] The cause of death National Health Insurance Corporation, Korea, 2008.

[28] "National Health Insurance Statistical Yearbook", National Health Insurance Corporation, Korea, 2008.

[29] Corporation of National Health Insurance, National Health Insurance System of Korea, Seoul, 2008.

[30] W.R. Kupchunas, "Personal health record: new opportunity for patient education", Orthop. Nurs.,vol.26,no,3,pp. 185-191,2007.

[31] S.P. Smith, A.C. "Barefield, Patients meet technology: the newest in patient-centered care initiatives", Health Care Manag. ,vol.26,no.4,pp. 354-362,2007.

[32] S.T. Liaw, "Patient and general practitioner perceptions of patient-held health records", Fam. Pract.,vol.10,no.4,pp. 406-415,1993.

[33] J. Webster, K. Forbes, S. Foster, I. Thomas, A. Griffin, H. Timms, "Sharing antenatal care: client satisfaction and use of the 'patient-held record"', Aust. N. Z. J. Obstet. Gynaecol,vol. 36,no.1,pp.11-14,1996.

[34] J.S. Wald, R.W. Grant, J.L. Schnipper, T.K. Gandhi, E.G. 
Poon, A.C. Businger, E.J. Orav, D.H. Williams, L.A. Volk, B. Middleton, "Survey analysis of patient experience using a practice-linked PHR for type 2 diabetes mellitus", AMIA Annu. Symp. Proc.,pp.678-682,2009.

[35] J. Hyne, Personal held records: "encouraging partnership with children and parents", Paediatr. Nurs.,vol.11,no.6,pp. 22-24,1999.

[36] S.E. Bae, H.Y. Kim, H.S. Son, H.S. Rhee, "Recognition of Personal Health Record", Journal of the Korea Academia-Industrial Cooperation

Society,vol.12,no.4,pp.1703-1710,2011.

[37] T. Liaw, M. Lawrence, J. Rendell, "The effect of a computer-generated patient-held medical record summary and/or a written personal health record on patients' attitudes, knowledge and behaviour concerning health promotion", Fam. Pract,vol.13,no.3,pp.289-293,1996.

[38] M. Wang, C. Lau, F.A. Matsen, Y. Kim, "Personal health information management system and its application in referral management", IEEE. Trans. Inf. Technol. Biomed.,vol.8,no.3,287-297,2004.
[39] W.B. Lober, B. Zierler, A. Herbaugh, S.E. Shinstrom, A. Stolyar, E.H. Kim, Y. Kim, "Barriers to the use of a personal health record by an elderly population", AMIA Annu. Symp. Proc.,pp.514-518,2006.

[40] S. R. Reti, H. J. Feldman, C. Safran, Governance for Personal Health Records, J Am Med Inform Association, vol.16,pp.14-17,2009.

[41] Hibbard JH, Mahoney ER, Stock R, et al. Do increases in patient activation result in improved self-management behaviors? Health Serv Res 2007;42:1443-63.[CrossRef][Medl ine][Web of Science]

[42] "Personal health records and hypertension control: a randomized trial"Peggy J Wagner1,2,3, James Dias4, Shalon Howard1, Kristina W Kintziger4, Matthew F Hudson2, Yoon-Ho Seol5, Pat Sodomkal J Am Med Inform Assoc doi:10.1136/amiajnl-2011-000349 Downloaded from jamia.bmj.com on May 22, 2012 - Published by group.bmj.com 